\title{
The gaps in health-adjusted life years (HALE) by income and region in Korea: a national representative bigdata analysis
}

\author{
Young-Eun Kim \\ National Health Insurance System \\ Minsu Ock \\ University of Ulsan College of Medicine \\ Hyesook Park \\ Ewha Womans University \\ Ki-beom Kim \\ Korea University \\ Dun-Sol Go \\ Korea Institute for Health and Social Affairs \\ Yoon-Sun Jung \\ Korea University \\ Seok-Jun Yoon ( $\square$ yoonsj02@korea.ac.kr) \\ Korea University https://orcid.org/0000-0003-3297-0071
}

Research article

Keywords: Health-adjusted life years, Inequality, Years lived with disability, Income, Region

Posted Date: July 27th, 2020

DOI: https://doi.org/10.21203/rs.3.rs-43599/v1

License: (a) This work is licensed under a Creative Commons Attribution 4.0 International License. Read Full License 


\section{Abstract}

Background: This study aims to calculate the health-adjusted life years (HALE) by using years lived with disability from the national claims data and aims to identify the differences and inequalities in income level and region.

Methods: The study was carried out on total population receiving health insurance and medical benefits. We calculated incidence-based years lived with disability (YLD) for 260 disease groups, and this was used as the number of healthy years lost to calculate HALE. We adopted the insurance premium to calculate the income as a proxy indicator. For the region classification, we chose 250 administrative districts to cover the whole country.

Results: The primary outcome was HALE in the Korean population. The second outcome was the HALE's gap in terms of income and region. HALE increased from 2008 to 2016. Results by gender suggest that HALE in males increases faster than in females. Results by income level show that HALE is higher in higher income level. In 2016, the gap in HALE between Q1 and Q2, the lower income group, was about 5.10 years. The gap in females by income level was smaller than that in males, which can be because males have greater inequality in terms of HALE by income level. Moreover, the gap in HALE by region was found to increase.

Conclusions: Results suggest that there is an inequality in years of living with disability in terms of income level in Korea. Therefore, we need intensive management for the low-income group to promote HALE at the national level.

\section{Background}

Health span is the length of time in one's life during which an individual is in a healthy state without any physical or mental disability. It is calculated by subtracting the period of disease prevalence from life expectancy. Various calculation methodologies exist to calculate the health span. These differ from each other based on the definition of health (prevalence of disease) and measuring approach. Disability-free life expectancy (DFLE), healthy life expectancy (HALE or HLE), health-adjusted life expectancy (HALE), and quality-adjusted life expectancy are among the approaches used to compute disability-adjusted life expectancy.

The World Health Organization (WHO) and the Institute for Health Metrics and Evaluation (IHME) report global health span by HALE-based approach. It is an important indicator to establish the Korean Health Plan and other national-level health policies. The Global Burden of Disease (GBD) Study in IHME calculates disease burdens of countries by gender, age, and illness through "estimation" based on published papers and other estimation methods for meta-regression. It means that epidemiologic parameters may not have measured coherently. The input value for calculating HALE is also a black box since IHME manages it internally. It is important to measure the years of healthy life lost through more accurate and consistent sources.

Previous studies have calculated HALE for Korean individuals [1, 2]. However, since they used the National Health and Nutrition Examination Survey data to measure the health loss, it has a limitation that only a narrow spectrum of diseases (45 diseases) was included in it. Additionally, it did not measure the socioeconomic health inequality. Broadening the spectrum of diseases is necessary to calculate accurate years of healthy life lost. We also need the review on data sources to obtain the reliability and coherence.

This study aims to calculate HALE by using years lived with disability (YLD) from national claims data and aims to identify the differences in income level and region.

\section{Methods}

\section{Data and units of analysis}

South Korea provides Universal Health Care (UHC) through national health insurance and public health benefit to all its nationals. As of January 2020, over 52 million people had received healthcare benefit, $97.2 \%$ of beneficiaries were under health insurance coverage, and $2.8 \%$ of people were public health beneficiaries. The NHIS claims database contains information about beneficiaries' medical uses, diagnosis, care start and end date, prescription details, and operation (surgery) details excluding out-of-pocket payment [3]. Therefore, in this study, we take the following steps to calculate HALE based on YLD. We have used the life table and cause of death data from Statistics Korea [4]. To calculate YLD, we used the NHIS claims data of all Koreans with Korean nationality living in Korea and National Hospital Discharge Survey by Korea Centers for Disease Control and Prevention (KCDC) with the period of $2008 \sim 2016$ [5].

We adopted the insurance premium to calculate the income as a proxy indicator. The NHIS scales insurance premiums based on subscribers' wages. Therefore, we used equivalized annual household income based on insurance premium in this study and divided it into quintiles by year and gender. Equivalized annual household income is derived as follows:

$$
\text { EquivalizedAnnualHouseholdIncome }=\frac{\text { AnnualHouseholdIncome }}{\text { NumberofHouseholdMember }^{0.5}}
$$

For the region classification, we chose 250 administrative districts to cover the whole country.

Loading [MathJax]/jax/output/CommonHTML/fonts/TeX/fontdata.js 
In this study, we calculated YLD by incidence-based approach by considering the prevalence, incidence, fatal, mortality, duration of disease, and disability weight for 260 disease groups, and this was used as the number of healthy years lost to calculate HALE [6].

\section{Statistical analysis}

The sum of YLD is mutually independently calculated by diseases used for HALE calculation. To reflect the loss of YLD due to comorbidity disease in the equation, we utilized the Monte-Carlo simulation to estimate the loss and finally calculated the HALE.

We used Sullivan's method to calculate HALE. It is expressed as the difference between life expectancy calculated from the whole population and mortality by age group and the years of healthy life lost derived from YLD. The WHO and IHME use the same method to estimate HALE [7, 8]. We calculated HALE from 2008 to 2016 depending on gender, income level, and region. In this study, to minimize the effect of outliers, we considered only the difference between 95th and 5th percentile while comparing the difference in HALE by regions.

We used SAS version 9.4 (SAS Institute Inc, Cary, NC, USA) for statistical analysis in this study.

\section{Results}

\section{HALE in Korea, by gender, income level, and year}

The HALE in Korea was 68.99 years in 2008 and increased to 70.56 years in 2016, that is, 1.67 years increase over 8 years (average 0.21 year per year). When we look HALE results by gender, in 2008, HALE for males was 66.47 years, and it increased by about 1.86 years to 68.33 years in 2016 ; while for females, it increased by 1.49 years from 71.00 in 2008 to 72.49 in 2016 . Our results reveal that females had faster HALE increasing rate than males during 2008-2016. We identified a decreasing trend in the gap between females and males: from 4.53 years in 2008 to 4.16 years in 2016 . In case of HALE by income level, the gap between 1st quintile and 5th quintile based on income level decreased from 2008 to 2012 as 7.94 years to 6.72 years; but after 2012, it increased to 7.58 years in 2016. HALE in Q1 increased by 1.97 years from 63.82 in 2008 to 65.78 in 2016 , while in Q2, it increased by 1.37 years, Q3 by 1.80 years, and Q4 by 1.80 years. In Q5, the highest income level group, it increased by about 1.61 years from 71.76 years in 2008 to 73.37 years in 2016. Our results reveal that HALE increases with increase in income level. The gap between Q1, the lowest income group, and Q2, the second lowest, was about 5.10 years in 2016 (Table 1).

Table 1

Annual HALE (unit: years) by gender and income level in Korea (2008-2016)

\begin{tabular}{|llllllllll|}
\hline & 2008 & 2009 & 2010 & 2011 & 2012 & 2013 & 2014 & 2015 & 2016 \\
\hline Overall population & 68.89 & 69.05 & 69.16 & 69.20 & 68.97 & 69.69 & 70.10 & 70.59 & 70.56 \\
\hline Gender & & & & & & & & & \\
\hline Male & 66.47 & 66.69 & 66.78 & 66.77 & 66.66 & 67.36 & 67.82 & 68.35 & 68.33 \\
\hline Female & 71.00 & 71.09 & 71.24 & 71.32 & 71.00 & 71.72 & 72.08 & 72.54 & 72.49 \\
\hline Difference & 4.53 & 4.40 & 4.46 & 4.54 & 4.34 & 4.36 & 4.26 & 4.20 & 4.16 \\
(Female-Male) & & & & & & & & & \\
\hline Income level & & & & & & & & 716 & \\
\hline Q1 (Lowest) & 63.82 & 64.06 & 64.53 & 64.72 & 64.76 & 65.25 & 65.58 & 66.00 & 65.78 \\
\hline Q2 & 69.52 & 69.53 & 69.43 & 69.42 & 69.25 & 70.03 & 70.37 & 70.80 & 70.89 \\
\hline Q3 & 69.61 & 70.66 & 70.59 & 70.63 & 70.33 & 71.08 & 71.47 & 72.00 & 71.98 \\
\hline Q4 & 70.39 & 70.66 & 70.59 & 70.63 & 70.33 & 71.08 & 71.47 & 72.00 & 71.98 \\
\hline Q5 (Highest) & 71.76 & 72.01 & 72.00 & 71.80 & 71.48 & 72.39 & 72.93 & 73.44 & 73.37 \\
\hline Difference & 7.94 & 7.95 & 7.47 & 7.08 & 6.72 & 7.14 & 7.35 & 7.44 & 7.58 \\
\hline Q1-Q5) & & & & & & & & & \\
\hline
\end{tabular}

\section{HALE by income level for males and females in Korea}

HALE by gender and income levels showed that HALE increased from 2008 to 2016 for all income levels for both males and females. Identified trends Loading [MathJax]/jax/output/CommonHTML/fonts/TeX/fontdata.js me level, HALE was 61.09 years in 2008, and it gradually increased by 1.95 years to 
63.04 years in 2016. At Q5, the highest income level, HALE increased by 1.99 years from 69.73 years in 2008 to 71.73 years in 2016 . For females, at Q1, HALE was 66.60 years in 2008, and it gradually increased by 2.02 years to 68.62 years in 2016. At Q5, HALE increased by 1.25 years from 73.29 years in 2008 to 74.54 years in 2016. For males, the gap in HALE according to income levels in 2008 was 8.64 years, which is similar to 8.68 years in 2016. On the other hand, for females, this gap decreased from 6.70 years in 2008 to 5.92 years in 2016. Males have a greater gap in HALE by income level than females. That is, inequality in HALE according to income level is considered to be greater in males (Fig. 1).

\section{Distribution Of The Hale By Region}

Results of HALE according to 250 administrative regions are as follows. The gap between 95th and 5 th percentile increased by 1.41 years from 4.88 years in 2008 to 6.29 years in 2016 . According to the gender classification, the gap in HALE for males increased by 2.41 years from 4.8 years in 2008 to 7.21 years in 2016, while, for females, it increased by 0.85 years from 5.05 years in 2008 to 5.90 years in 2016 . The gap in HALE by region was considered as increasing (Fig. 2).

\section{Discussion}

This study presents HALE based on YLD calculated from 2008 to 2016 using national claims data. We computed the gap in HALE by gender and income level to measure the equity of HALE. HALE increased from 2008 to 2016, and results by gender suggest that HALE in males increase faster than in females. Results by income level reveal that HALE is higher in higher income level. The gap in HALE between Q1 and Q2, the lower income group, was about 5.10 years in 2016. The gap by income level in females was smaller than in males, which can be because males have greater inequality in terms of HALE according to income level. The gap in HALE between regions widened over time.

The gap in life expectancy by gender decreased from 6.55 years in 2008 to 6.10 years in 2016 [9]. The gap in life expectancy by income level also decreased from 6.9 years in 2008 to 6.59 years in 2016 . According to the results, the gap in gender has been on the decline from 4.53 in 2006 to 4.16 in 2016, and the gap based on income levels has decreased from 7.94 in 2008 to 6.72 in 2012, thereafter increasing to 7.58 years in 2016 . Especially, the lowest income level group has lower HALE compared to other quintiles. Several studies show that smoking, alcohol usage, and other health behaviors of the low-income bracket are worse than other brackets [10-12]. We need intensive management for the low-income group to promote HALE at the national level. Research is needed on how to set goals for managing health hazards by calculating PAF (population attributable fractions), a fraction that major health hazards such as smoking, drinking, and obesity contributed to YLD, and improving HALE by preventing certain diseases.

This study suggests that the regional gap in HALE keeps increasing. South Korea has the lowest birthrate and the fastest aging population rate in the world, and the income gap between regions is also deepening. The gap in QALE by regions is correlated with socioeconomic characteristics, smoking, and health infrastructure related indicators [2]. Therefore, there is a need for further research to identify the origin of regional HALE gap. Moreover, we need research that reveals the association with the distribution of infrastructure on HALE. Through the research revealing this association, we can develop evidence of medical resources allocation for HALE promotion in areas with low HALE.

Based on the result of YLD, the difference between life expectancy in Korea suggested from the study of Khang et al. (2019) and HALE from this study is as follows [9]. We found an increase of 1.25 years from 11.15 years in 2008 to 12.40 years in 2016 . For males, 1.30 years increased from 10.04 years in 2008 to 11.34 years in 2016 . For females, there was an increase of 1.22 years from 12.06 years in 2008 to 13.28 years in 2016 .

The difference in life expectancy is 6.10 years in 2016, but the difference in HALE is smaller as 4.16 years in the same period. That is, females relatively have more YLD than males. In 2016, Q1 spent 13.26 years, while Q5 spent 12.26 years in terms of time spent in an unhealthy state; and the difference between the two groups was 0.99 years. The results suggest that there is an inequality in YLD in terms of income level in Korea.

South Korea's HALE from GBD 2016 in 2016 was 68.49 years for males and 72.97 years for females, and YLD for males was 11.25 years and for females was 9.18 years [13]. The facts that females have a higher HALE and higher YLD than males matched the results of this study. Moreover, derived HALE in this study (70.56 years) is similar to the HALE from GBD 2016 (70.76 years). However, South Korea's HALE in 2016 from GBD 2017 is 71.57 years (69.59 years for males, 73.37 years for females), and it increased by about 0.81 years from GBD 2016 [13]. This difference between the GBD Study and this study is caused by the adoption of the procedure of input variable estimation by WHO and IHME.

The WHO also calculates HALE based on YLD from GBD Study. The WHO currently presents South Korea's HALE in 2016 as 73.0 years (70.7 years for males, 75.1 years for females). In 2015, the WHO's HALE for South Korea was 72.7 years (70.3 years for males, 74.8 years for females) [14, 15]. It was updated based on World Health Statistics 2018 on April 6, 2018, but South Korea's HALE in 2015 was presented as 73.2 years using World Health Statistics 2016 [16]. Limitations mentioned above make it difficult for individual countries to develop and evaluate the health goal using HALE as a national indicator. Therefore, when establishing and evaluating Korea's policy, data-driven YLD is more compatible than model-driven YLD, which the WHO and IHME have adopted. Additionally, HALE from the WHO and IHME can be used as a powerful indicator for a comparative study between countries, but it is not being produced in terms of equity, such as income in individual countries or regional differences in HALE.

Loading [MathJax]/jax/output/CommonHTML/fonts/TeX/fontdata.js 


\section{Conclusions}

This study has some limitations. When calculating HALE in a small area, some outliers occurred in HALE due to the lack of population and deaths. In future, it will be necessary to develop a methodology for HALE calculation in small areas. In this study, equivalized annual household income was used, but it is necessary to discuss whether household income is identified with individual income.

However, through the study, we were able to verify HALE's capability as a measure of equity. This study is the first HALE study derived from national data for the whole population.

\section{List Of Abbreviations}

Disability-free life expectancy (DFLE)

Global Burden of Disease (GBD)

Health-adjusted life years/expectancy (HALE)

Healthy life expectancy (HLE)

Institute for Health Metrics and Evaluation (IHME)

Korea Centers for Disease Control and Prevention (KCDC)

Population attributable fractions (PAF)

UHC (Universal Health Care)

World Health Organization (WHO)

Years lived with disability (YLD)

\section{Declarations}

\section{Ethics approval and consent to participate}

This study was approved by the National Health Insurance Service of Korea (No. NHIS-2019-1-182) and the Institutional Review Board (IRB) of Korea University (IRB No. KU-IRB-18-EX-51-A-1). The board waived informed consent.

\section{Consent for publication}

Not applicable

\section{Availability of data and materials}

All data are available from the corresponding author upon reasonable request.

\section{Competing interests}

The authors declare that they have no competing interests.

\section{Funding}

This research was supported by a Korea Health Technology R\&D Project grant through the Korea Health Industry Development Institute (KHIDI), funded by the Ministry of Health \& Welfare, Republic of Korea (grant number: HI18C0446). The funding body did not have any role in the design of the study; collection, analysis, and interpretation of data; and in writing the manuscript.

\section{Authors' contributions}

YEK and SJY conceived and designed the study. YEK, MSO, HSP, DSG, KBK, and YSJ acquired the data and drafted the initial manuscript. All authors contributed to analyzing the data, interpreting the results, and revising the manuscript. The corresponding author attests that all listed authors meet authorship criteria and that no others meeting the criteria have been omitted.

\section{Acknowledgments}

Not Applicable 


\section{References}

1. Lee JY, Ock M, Kim SH, Go DS, Kim HJ, Jo MW. Health-adjusted life expectancy (HALE) in Korea: 2005-2011. J Korean Med Sci. 2006;31 Suppl 2:S139-45.

2. Lim D, Bahk J, Ock M, Kim I, Kang HY, Kim YY, et al. Income-related inequality in quality-adjusted life expectancy in Korea at the national and district levels. Health Qual Life Out. 2020;18(1):1-8.

3. National Health Insurance System. https://www.nhis.or.kr/menu/retriveMenuSet.xx?menuld=B2220. Accessed 02 July 2020.

4. Statistics in Korea. http://kosis.kr/statHtml/statHtml.do? orgld=101\&tblld=DT_1B42\&vw_cd=MT_ZTITLE\&list_id=A5\&seqNo=\&lang_mode=ko\&language=kor\&obj_var_id=\&itm_id=\&conn_path=MT_ZTITLE. Accessed 02 July 2020.

5. Korea Centers for Disease Control and Prevention. Injury Surveillance. Available from: http://www.cdc.go.kr/CDC/contents/CdcKrContentView.jsp? cid=26611\&menulds=HOME001-MNU1130-MNU1110-MNU1117-MNU1467. Korean. Accessed 02 July 2020.

6. Kim YE, Park H, Jo MW, Oh IH, Go DS, Jung J, et al. Trends and patterns of burden of disease and injuries in Korea using disability-adjusted life years. J Korean Med Sci. 2018;34 Suppl 1.

7. World Health Organization. WHO methods for life expectancy and healthy life expectancy. Global Health Estimates Technical Paper WHO/HIS/HSI/GHE. 2014.

8. Kyu HH, Abate D, Abate KH, Abay SM, Abbafati C, Abbasi N, et al. Global, regional, and national disability-adjusted life-years (DALYs) for 359 diseases and injuries and healthy life expectancy (HALE) for 195 countries and territories, 1990-2017: a systematic analysis for the Global Burden of Disease Study 2017. Lancet. 2018;392(10159):1859-922.

9. Khang YH, Bahk J, Lim D, Kang HY, Lim HK, Kim YY, et al. Trends in inequality in life expectancy at birth between 2004 and 2017 and projections for 2030 in Korea: multiyear cross-sectional differences by income from national health insurance data. BMJ Open. 2019;9(7), e030683.

10. Kim I, Bahk J, Yoon TH, Yun SC, Khang YH. Income differences in smoking prevalences in 245 districts of South Korea: patterns by area deprivation and urbanity, 2008-2014. J Prev Med Public Health. 2017;50(2):100.

11. Kwak CW, Han KT, Nam CM, Moon KT, Yoon HS, Park EC. Income disparity and mortality among patients with alcohol use disorder in South Korea. Psychiatry Res. 2017;258:358-64.

12. Kim IG, So WY. The relationship between household income and physical activity in Korea. J Phys Ther Sci. 2014;26(12):1887-9.

13. GBD Compare. https://vizhub.healthdata.org/gbd-compare/. Accessed 02 July 2020.

14. WHO Global Health Observatory Data Repository. http://apps.who.int/gho/data/view.main.HALEXv?lang=en]. Accessed 02 July 2020.

15. World Health Organization. World health statistics 2018: monitoring health for the SDGs. Geneva, 2018. 2018.

16. World Health Organization. World health statistics 2016: monitoring health for the SDGs sustainable development goals. 2016.

\section{Figures}

(unit: years)

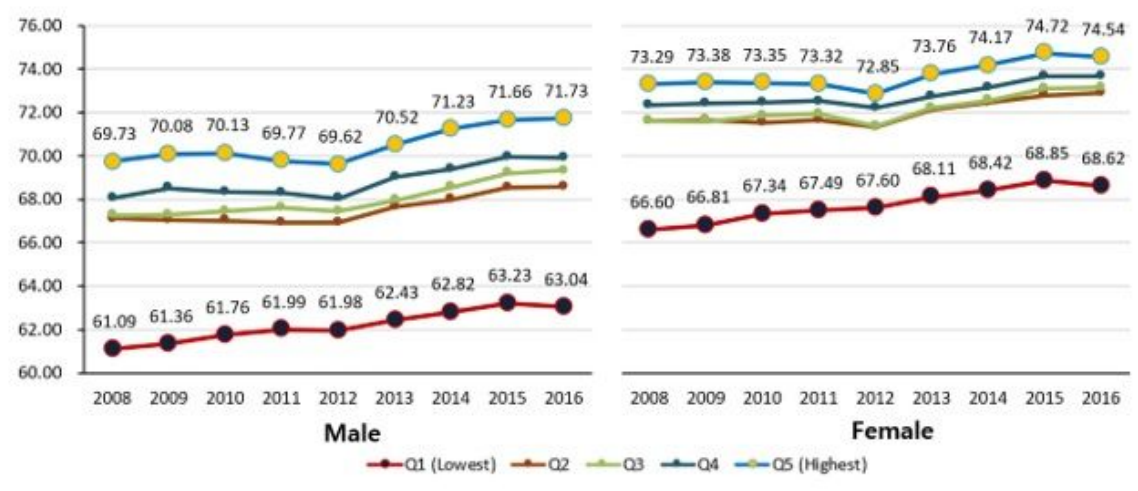

Figure 1

The HALE by income level for males and females in Korea (2008-2016) 


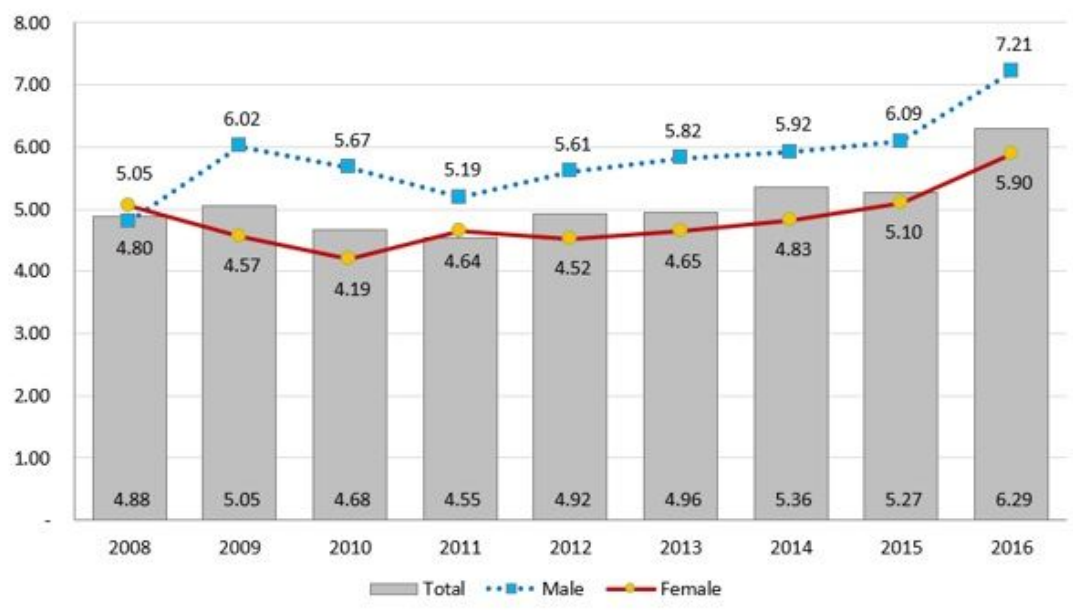

Figure 2

Difference (95th and 5th percentile) of HALE for males and females by region in Korea 